\title{
Evaluation and measurement of performance, practice and pressure of green supply chain in Indian manufacturing industries
}

\author{
Tina Chaudhary ${ }^{\mathbf{a}^{*}}$ and Arindam Kumar Chanda ${ }^{\mathrm{b}}$
}

${ }^{a}$ Department of Mechanical \& Automation Engineering, IGDTUW, Delhi, India

${ }^{b}$ Working as Associate Professor in Mechanical \& Automation Engineering department in G.B. Pant Engineering College, Delhi

\begin{tabular}{l}
\hline C H R O N I C L E \\
\hline Article history: \\
Received March 18, 2015 \\
Accepted May 25 2015 \\
Available online \\
May 27 2015 \\
\hline Keywords: \\
Green Manufacturing \\
Environmental performance \\
Practice and pressure \\
Factor analysis \\
Mean score
\end{tabular}
\begin{abstract}
A B S T R A C T
Green supply chain is a new concept in recent literature. The purpose of the study is to identify the importance of different factors related to green practice, performance and pressure during manufacturing in Indian manufacturing industries. The approach of this research includes in depth literature review, experts interviews and questionnaire surveys. The questionnaires are developed and data are collected through mail and two rounds of data collection were carried out to obtain more reliable responses. The major activities of the green supply chain; namely internal environmental management system, green packaging, green purchasing, eco designing, cooperation with customers, internal recovery, environmental, positive economic, negative economic, regulatory, competition are covered throughout the research. Factor analysis is performed using IBM SPSS 21 statistical software to understand the importance of green supply chain. Factor analysis is used to obtain the relative importance of various factors of green practice, green performance, and pressure. The collected data are analyzed by applying "mean score" method and the graphs are designed in SPSS software to compare the different factors.
\end{abstract}

\section{Introduction}

Every industry whether it is small medium or large, ultimately comes to make profit. It needs a perfect optimization and balance in many aspects like government regulation, market condition, customer's demand, investors' support and many other things. Industries generally ignore the environmental aspects to maintain these aspects, they degrade the environment directly or indirectly and it also adversely influences the daily life of human being. Many years ago, the concept of green supply chain management was nonexistent for industries. However, the quality revolution of the 1980s and the supply chain revolution of the 1990s have made it evident that the business best practices call for integration of environmental management parallel with ongoing operations. Then a concept of green supply chain management comes into picture. It is a very new idea for industries and among researchers. Green supply chain management is greening all processes in supply chain. Green supply 
chain management increases the productivity and profit. GSCM reduces the harmful effects of manufacturing industries on environment. GSCM is divided into three categories i.e. green practices, performance and pressure. These categories include many factors. The major activities of green practice are internal environmental management system, green purchasing, green packaging, eco designing, cooperation with customers and internal recovery. The major activities of green performance are environmental, positive economic and negative economic. The major activities of green pressure are regulatory and competition. Many definition have been purposed but each has the same meaning and focus to same objective of cost reduction and sustainable development of all enterprises.

This study explains the implementation of practices, performance and pressure of GSCM among various manufacturing industries in India. There are three categories in this study as described above. These categories are divided into subcategories, each subcategory has some questions and 56 questions are designed. After introduction, in section 2, literature review is given. Section 3 contains research methodology while the results and analysis of various factors of GSCM by factor analysis and mean score are presented in section 4 . Finally, section 5 presents the conclusion.

\section{Literature review}

Green Supply Chain Management (GSCM) is defined as the management of the parts or components, raw materials and processes from suppliers to manufacturers and manufactures to customers and the products take back with improvements to environmental impacts through life cycle stages. (Hu \& Hsu, 2010). Sarkis et al. (2005) defined GSCM by adding the green components to supply chain and hence it involved addressing the impact and relationships of supply chain management to the natural environment. Most studies in the concept of green supply chain management have emphasized remanufacturing, reduction, recycling, product design, procurement and manufacturing practice.

Muma et al. (2014) conducted a study on green supply chain management (GSCM) and environmental performance among the tea processing firms in Kericho County, Kenya. The study adopted a correlation study design and applied multiple regression model to establish the effect of GSCM on environmental performance. ANOVA test was also performed to determine the statistical significance of relationship between the variables. The study shows that GSCM had positive effect on environmental performance. Huang et al. (2012) conducted a study on the pressure on GSCM by analyzing the pressures for adopting GSCM among Chinese small and medium-sized enterprises. They reported that all the pressure from the environmental laws and regulations, the pressure in the supply chain management in the relation with suppliers and customers and the pressure in the process of selling the products could influence on the decisions of small and medium sized enterprises to employ GSCM practices. Bhateja et al. (2011) conducted a study for various activities of the supply chain management processes of various Indian manufacturing firms. They detected six major activities of the green supply chain; namely green procurement \& sourcing, green warehousing green manufacturing, green distribution, green packaging (eco packaging), green transportation. Deif (2011) designed a system model for the green manufacturing paradigm. He developed an open mixed architecture for the designing, planning and controlling of the green manufacturing activities. The model included various planning activities to migrate from less green into greener and more eco-efficient manufacturing process. Deshmukh and Sunnapwar (2013) conducted a study on the development and validation of performance measure of green supplier selection in the industries. Factor analysis and mean score method were conducted to analyze relative importance of the factors. They reported that quality was the most important criteria followed by the environmental performance, green manufacturing, and customer cooperation. Agarwal and Vijayvargy (2012) presented a methodology to evaluate supplier's selection using an analysis based on the analytic network process (ANP) and environmental factors. The study consisted of four main criteria or dimensions including operational life, overall performance, environmental friendly, and process management. Büyüközkan and Çifçi (2012) examined Green supply chain and GSCM capability dimensions to define an evaluation framework for green suppliers. The components were integrated into a novel hybrid fuzzy multiple criteria decision making (MCDM) 
model combining the fuzzy Decision Making Trial and DEMATEL (Evaluation Laboratory Model), the ANP, and TOPSIS in a fuzzy context. The combined fuzzy DEMATEL and fuzzy ANP approaches offered a more accurate and precise analysis. Meera and Chitramani (2014) conducted a study on the Environmental Sustainability through GSCM practices among Indian Manufacturing industries. The study was conducted on survey and investigated the pressures to implement GSCM practices and the relationship between green supply chain practices and environmental Performance and they reported a positive relationship between the constructs. It indicated that GSCM practices could improve environmental performances. Kumar et al. (2012) investigated the GSCM practices likely to be adopted by the Indian manufacturing industry of electrical and electronics products and the relationship between GSCM practices and environmental performance was detected and they reported the performance of eco accounting, eco procurement, eco logistics design, eco manufacturing, eco product design, and economic performances, its practices in response to the national \& international green issues. Toke and Gupta (2010) gave details of the investigation, practice and evaluation of GSCM. The research included functions like purchasing and inbound logistics, distribution and out-bound logistics, production and reverse logistics. Chandraker and Kumar (2013) evaluated and measured the performance of GSCM in Chhattisgarh manufacturing industries. In this paper Multi Criteria decision making method (MCDM) was used to determine GSCM performance. Fuzzy comprehensive method has been used to obtain the performance having different operational, environmental, economic performance parameters, comparing the comprehensive after getting performance. The result indicated that the manufacturing performance could be improved after the implementation of GSCM. Wu et al. (2012) used the Evaluation Laboratory (DEMATEL) method and the fuzzy Decision Making Trial to find the factors in selecting green supply chain management criteria. Liu et al. (2005) developed a FMADM (fuzzy multiple attribute decision-making method) with a three level hierarchical decision making model to get the aggregate risk in green manufacturing projects. Chen et al. (2012) designed a network to define managerial levels and firm related contents. It defined four business functions from the product lifecycle management: purchasing, design, manufacturing, marketing and service. It also showed the related activities with greenness. Awasthi et al. (2010) proposed a fuzzy multi criteria approach to evaluate the environmental performance of suppliers. The proposed approach consisted 12 criteria. Humphreys et al. (2003) presented a model for integrating environmental factors into supplier selection process. Subsequently, a framework for the supplier selection was developed which incorporated environmental performance. Chan (2011) described the development in production and operations management. Green processing and product designing was chosen as the main theme. Some cases conducted by the author, including eco-design, reverse logistics, and so on, are employed to show how product design and green process can be done in practice. Yeh and Chuang (2011) proposed a mathematical model for the selection of green suppliers which includes different objectives. Lin et al. (2012) developed a green purchasing system by using the ANP and linear programming methods. The ANP was performed for the selection of green suppliers. It consisted criteria like pollution reduction, energy saving, social responsibility etc. Govindan et al. (2013) defined components and elements of GSCM. The decision framework was designed and solved as an ANP.

\section{Research methodology}

The objective of the study is to investigate practice, performance and pressure of GSCM in Indian manufacturing industries. The aim is to select the best factors of green supply chain. The questionnaire was designed after literature review. Based on the literature review, a list of criteria was designed for GSCM. Practicing industries were consulted for their view on the selected criteria where all the relevant criteria were introduced in the questionnaire in pretesting phase of the questionnaire. Based on their feedback, three categories were designed i.e. Practice, performance and pressure. Categories were divided into subcategories. Questions were designed for each subcategory. There were 56 questions and each question was judged on a 5 point Likert Scale, where, $1=$ very low, 2 = low, $3=$ moderate, 4 $=$ high and $5=$ very high. Likert scale is a tried and successfully scale that is used in many cases. The reliability test was conducted IBM SPSS 21 software. The responses were obtained from various 
manufacturing industries, automobile industries, oil industries, chemical industries, machinery industries and power plant industries. The reliability test was performed to obtain accurate data. The most easy and common method to obtain reliability is Cronbach's alpha test that is conducted in SPSS. This statistic indicated the correlation of the items that make up the scale. The value lies between 0 and 1. Higher value indicates more reliability. Up to value 0.7 , Reliability is good. Cronbach's alpha depends on the number of items on the scale. If the number of item on scale is less than 10 than the value of Cronbach's alpha will be small. If the value of Cronbach's alpha is less than 0.7, reject the data. Factor analysis was performed using Statistical Package for the Social Sciences (SPSS) software. Mean score was calculated for all the factors. Then graphs are designed to make comparison between different factors.

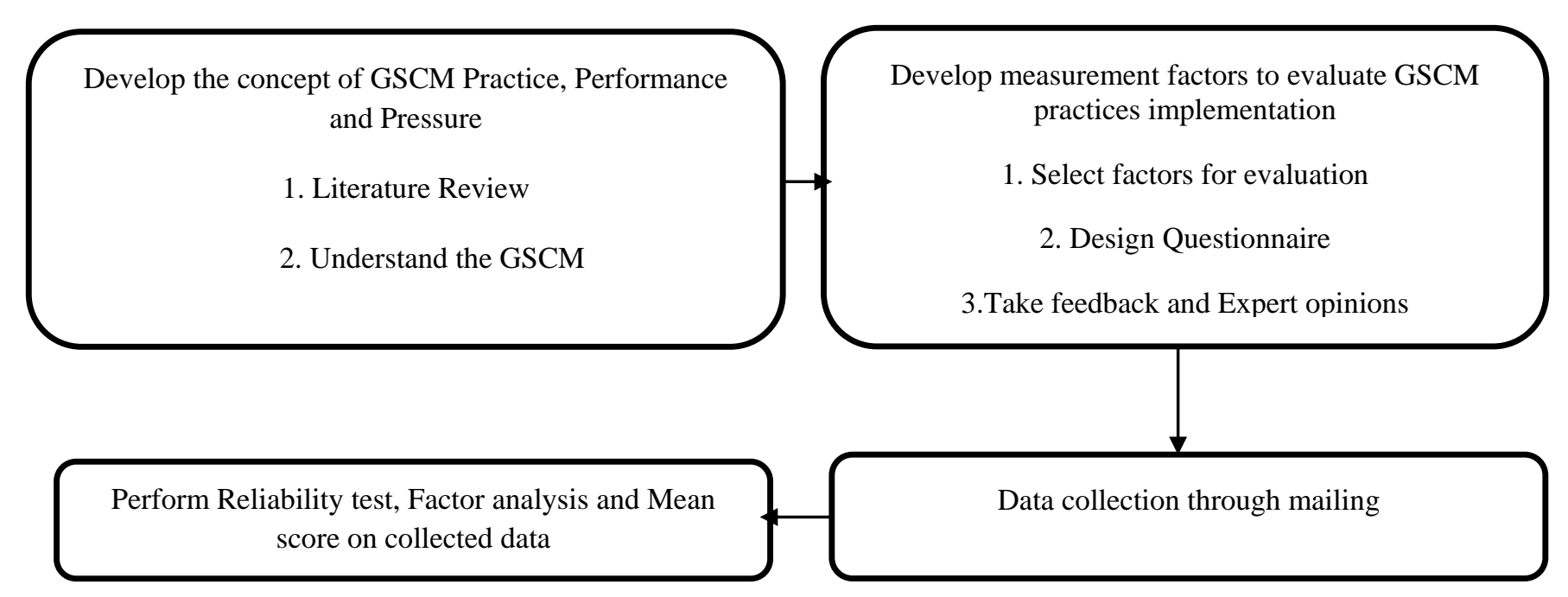

Fig. 1. Flow Chart of Methodology

\section{Comparative factor analysis}

\subsection{Reliability analysis}

Reliability shows the extent up to which an experiment yield the same result. Reliability analysis was performed on 56 criteria using IBM SPSS software. The scale chosen should be free from random error. The final Cronbach's alpha value will give idea about the random error. The Cronbach's alpha value should be more than 0.7 .

Table 1

Cronbach's alpha value of factors

\begin{tabular}{ll}
\hline Criteria & Final Cronbach’s alpha value \\
\hline Green Practice & 0.844 \\
Green Performance & 0.791 \\
Green Pressure & 0.811 \\
\hline
\end{tabular}

Table 2

Cronbach's alpha value of entire values

\begin{tabular}{cc}
\hline Cronbach's Alpha & N of Items \\
\hline 0.960 & 56 \\
\hline
\end{tabular}


Cronbach alpha value for each category is given separately in Table 1.The final Cronbach alpha value for each category is more than the required minimum value. The Cronbach alpha value for overall questionnaire is given in Table 2.The Cronbach's alpha value is 0.960 i.e. greater than 0.7.The final Cronbach's value proves that the scale chosen is free from random error and sub- criteria are properly assigned to their respective criteria.

\subsection{KMO and Bartlett's tests of Sphericity}

The next appropriateness to perform factor analysis was obtained by examining the strength of the relationships among the sub criteria. This was conducted by the coefficients in the correlation matrix, the KMO (Kaiser-Meyer-Olkin) and Bartlett's test of Sphericity. The Bartlett's test of Sphericity should be significant $(\mathrm{p}<0.05)$ to perform factor analysis. KMO value lies between 0 -1.The minimum recommended value of KMO is $0.6 . \mathrm{KMO}$ value more than 0.5 is optimal.

\section{Table 3}

KMO and Bartlett's test of sphericity for Green Practice

\begin{tabular}{lll}
\hline Criteria & KMO & Bartlett's test \\
\hline Internal Environmental Management System & 0.869 & 0.00 \\
Green Purchasing & 0.784 & 0.00 \\
Green Packaging & 0.720 & 0.00 \\
Eco Designing & 0.845 & 0.00 \\
Cooperation with Customers & 0.770 & 0.00 \\
Internal Recovery & 0.682 & 0.00 \\
\hline
\end{tabular}

\section{Table 4}

KMO and Bartlett's test of Sphericity for Green Performance

\begin{tabular}{lll}
\hline Criteria & KMO & Bartlett's test \\
\hline Environmental & 0.896 & 0.00 \\
Positive Economic & 0.795 & 0.00 \\
Negative Economic & 0.724 & 0.00 \\
\hline
\end{tabular}

\section{Table 5}

KMO and Bartlett's test of Sphericity for Green Pressure

\begin{tabular}{lll}
\hline Criteria & KMO & Bartlett's test \\
\hline Regulatory & 0.815 & 0.00 \\
Competition & 0.719 & 0.00 \\
\hline
\end{tabular}

Analysis of KMO value using IBM SPSS proves that all the values meet the required standard. Bartlett's values $(\mathrm{p}<0.05)$ shows that all the criteria are significant. Factor analysis test can perform.

\subsection{Factor analysis}

Factor analysis was performed on each criterion and sub-criterion. The values were extracted in SPSS software using principal component analysis (PCA) with Varimax rotation. Factors with Eigen value over 1 is extracted. Scree plot with unrotated factor solution was analyzed. These factors with a significant slope above the bend were extracted in the scree plot. The scree plot for Green practice, performance and pressure is shown below in Fig 2 and Fig 3. 


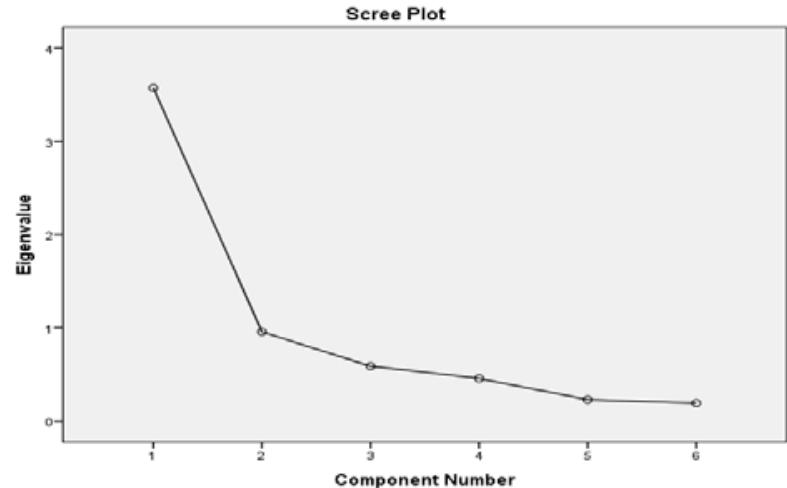

Fig. 2. Scree plot of Green Practice

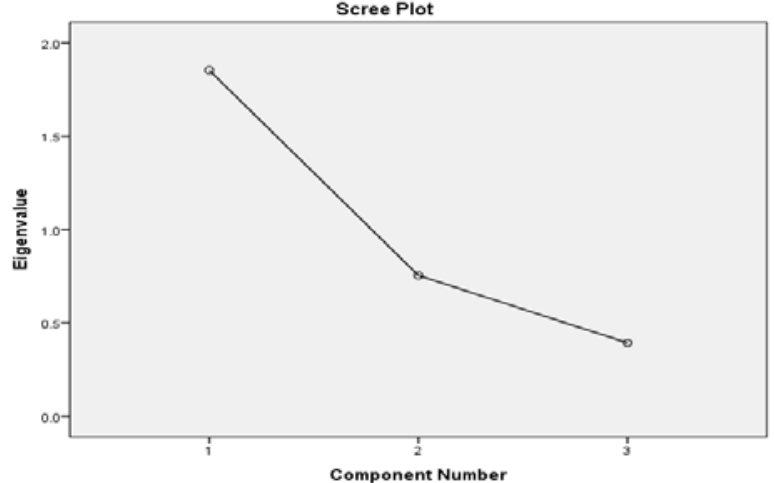

Fig. 3. Scree plot of Green Performance

\section{Table 6}

Result of factor analysis for Green Practice

\begin{tabular}{lccc}
\hline Criteria & Eigen Value & \% Variance & Factors Extracted \\
\hline Internal Environmental Management & 5.028 & 55.866 & 2 \\
System & 1.200 & 13.388 & 1 \\
Green Purchasing & 3.062 & 61.242 & 1 \\
Green Packaging & 2.388 & 59.698 & 1 \\
Eco Designing & 3.973 & 5.755 & 1 \\
Cooperation with Customers & 3.437 & 68.731 & 1 \\
Internal Recovery & 1.951 & 65.043 & \\
\hline
\end{tabular}

\section{Table 7}

Result of Factor analysis for Green Performance

\begin{tabular}{llll}
\hline Criteria & Eigen Value & \% Variance & Factor Extracted \\
\hline Environmental & 3.990 & 79.795 & 1 \\
Positive Economic & 3.423 & 68.463 & 1 \\
Negative Economic & 2.225 & 55.623 & 1 \\
\hline
\end{tabular}

\subsection{Importance of mean criteria in terms of mean value}

Mean values were calculated using SPSS in order to find out the importance of criteria in Indian manufacturing industries. Table 8, Table 15 and Table 19 show the mean values and standard deviations of different criteria of green practice, performance and pressure obtained from various respondent. Higher mean values are associated with the most important criteria. Lower mean value indicates the least important criteria.

Table 8

Importance of the Major criteria of Green Practice

\begin{tabular}{lll}
\hline Criteria & Mean & Standard Deviation \\
\hline Internal Environmental Management System & 3.70 & 1.003 \\
Green Purchasing & 3.57 & 0.996 \\
Green Packaging & 3.70 & 0.928 \\
Eco Designing & 3.74 & 0.862 \\
Cooperation with Customers & 3.93 & 0.890 \\
Internal Recovery & 3.80 & 0.986 \\
\hline
\end{tabular}

The most important criterion is cooperation with customers with the highest mean value of 3.93 in green practice. The least important criteria is associated with green purchasing with mean value 3.57. 
Table 9

Mean and Standard deviation of Sub criteria of Internal Environmental Management System

\begin{tabular}{lll}
\hline Sub Criteria & Mean & Standard Deviation \\
\hline Do your senior managers support for GSCM? & 3.86 & 1.111 \\
Do your junior and midlevel managers support for GSCM? & 3.60 & 1.196 \\
Is your organization certified by ISO14001? & 4.03 & 1.539 \\
Do you make eco labeled products? & 3.16 & 1.567 \\
Does environmental management system exist in your organization? & 4.07 & 1.234 \\
Does your organization have team to solve environmental issues? & 3.93 & 1.294 \\
Does your organization publish periodic white paper/environmental report? & 3.16 & 1.493 \\
Does your organization establish long term environmental objectives? & 3.79 & 1.365 \\
\hline Is there any provision of training on environmental management in your organization? & 3.67 & 1.419 \\
\hline
\end{tabular}

The most important sub-criterion in internal environmental management category is associated with "existence of environmental management system in organization" with mean value 4.07 and the least important sub criteria is publishing of white paper.

\section{Table 10}

Mean and Standard deviation of Sub criteria of Green Purchasing

\begin{tabular}{lll}
\hline Sub Criteria & Mean & Median \\
\hline Does your organization purchase the raw material from ISO14000 certified supplier? & 3.28 & 1.406 \\
Do you cooperate with suppliers for environmental issues? & 3.81 & 1.074 \\
Is there any environmental audit for internal management of suppliers? & 3.35 & 1.435 \\
Do you purchase environmental friendly products? & 3.79 & 1.163 \\
Do you consider environmental criteria for supplier selection? & 3.61 & 1.294 \\
\hline
\end{tabular}

The most important sub-criterion in green purchasing is cooperation with suppliers for environmental issues with mean value 3.81.The least important sub-criterion is associated with purchase of raw material from ISO14000 certified supplier with mean 3.28.

\section{Table 11}

Mean and Standard deviation of Sub criteria of Green Packaging

\begin{tabular}{lll}
\hline Sub Criteria & Mean & Standard Deviation \\
\hline Does your organization recycle and reuse outer packaging in logistics process? & 3.55 & 1.389 \\
Does your organization use ecological material for inner packaging? & 3.62 & 1.210 \\
$\begin{array}{l}\text { Do you agree that there is a minimization of the use of material for packaging in you } \\
\text { organization? }\end{array}$ & 3.87 & 1.038 \\
\hline
\end{tabular}

The most important sub-criteria in green packaging is minimization of use of material for packaging.

\section{Table 12}

Mean and Standard deviation of Sub criteria of Eco Designing

\begin{tabular}{lcc}
\hline Sub Criteria & Mean & Standard Deviation \\
\hline $\begin{array}{l}\text { Do you agree that there is a reduction of consumption of material for designing of } \\
\text { products? }\end{array}$ & 3.77 & 1.199 \\
$\begin{array}{l}\text { Does your organization reuse, recycle and recover the components parts material? } \\
\text { Does your organization design the product to reduce the use of hazardous products? }\end{array}$ & 3.74 & 1.05 \\
$\begin{array}{l}\text { Does your organization minimize the use of natural resources during manufacturing? } \\
\text { Does your organization design the product to use less area for storage? }\end{array}$ & 3.79 & 1.144 \\
\hline $\begin{array}{l}\text { Does your organization design the product for easy setup in most energy saving way? } \\
\text { Does your organization use renewable energy resources for manufacturing } \\
\text { operations? }\end{array}$ & 3.78 & 1.023 \\
$\begin{array}{l}\text { Does your organization consider the environmental issues during the selection of } \\
\text { manufacturing process? }\end{array}$ & 3.73 & 1.031 \\
\hline
\end{tabular}


The most important sub-criterion in Eco Designing is designing of the product to reduce the use of hazardous material with mean 4.05 and least important sub-criteria is use of renewable energy resources for manufacturing operation with mean 3.28.

Table 13

Mean and Standard deviation of Sub criteria of Cooperation with Customers

\begin{tabular}{lcc}
\hline Sub Criteria & Mean & Standard Deviation \\
\hline Do you cooperate with customers for eco-design? & 3.94 & 1.045 \\
Do you cooperate with customers for cleaner production? & 4.06 & 1.071 \\
Do you cooperate with customers for green packaging? & 3.96 & 1.063 \\
Do you cooperate with customers for green logistics? & 3.96 & 1.054 \\
Do you cooperate with customers for reverse logistics? & 3.75 & 1.158 \\
\hline
\end{tabular}

The most important sub-criteria is cooperation with customers for cleaner production with mean value 4.06 and the least important sub-criteria is cooperation for reverse logistics.

\section{Table 14}

Mean and Standard deviation of Sub criteria for Internal Recovery

\begin{tabular}{lll}
\hline Sub Criteria & Mean & Standard Deviation \\
\hline Does your organization sell the extra inventories? & 3.50 & 1.291 \\
Does your organization sell the waste/scrape and used material? & 4.13 & 1.091 \\
Does your organization sell the excess equipment? & 3.77 & 1.285 \\
\hline
\end{tabular}

The most important sub criterion for internal recovery is selling of waste/scrape and used material. Its mean value is highest.

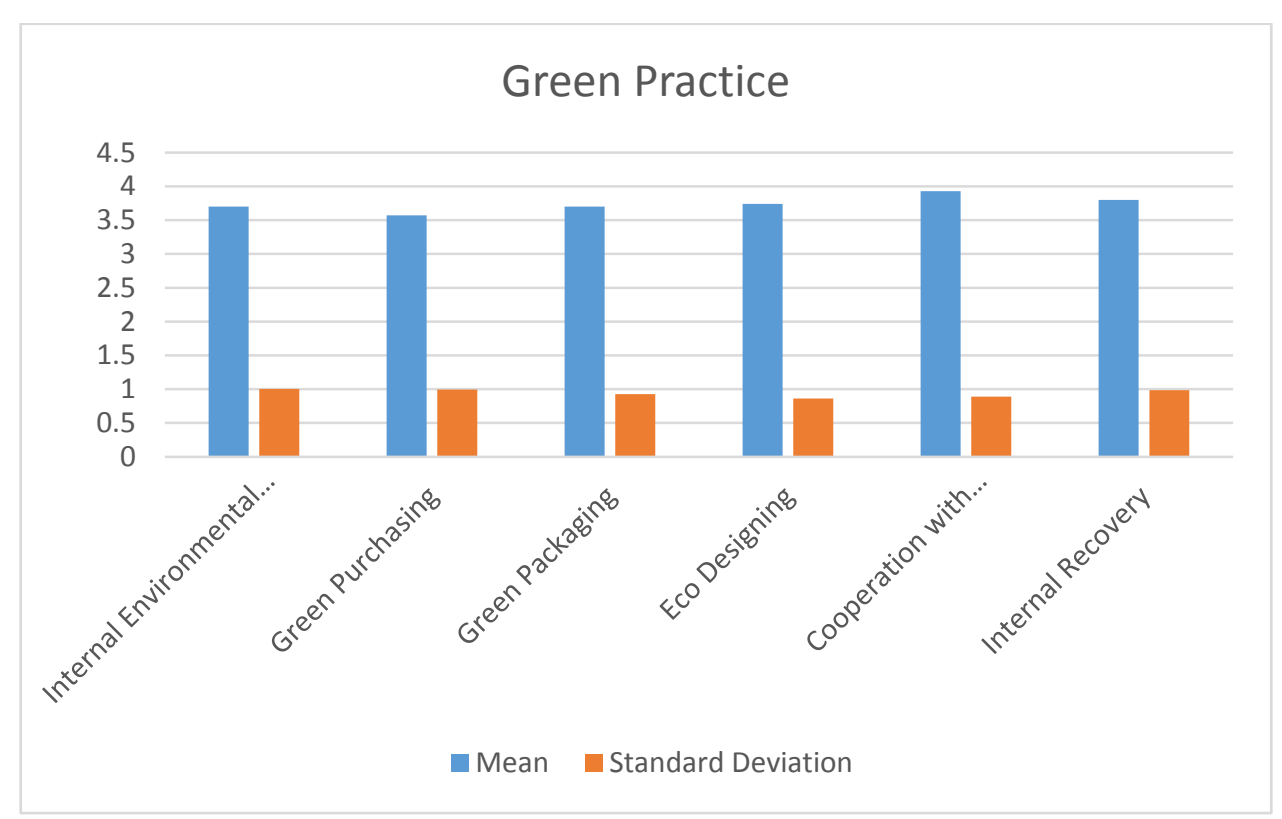

Fig. 4. Importance of the major criteria of Green Practice in Indian Industries

Table 15

Importance of the Major criteria of Green Performance.

\begin{tabular}{lll}
\hline Criteria & Mean & Standard Deviation \\
\hline Environmental & 4.05 & 1.000 \\
Positive Economic & 3.56 & 0.966 \\
Negative Economic & 3.61 & 0.810 \\
\hline
\end{tabular}


The most important criterion is environmental criteria with mean of 4.05 in case of green performance and the least important criterion is associated with positive economic.

Table 16

Mean and Standard deviation of sub criteria for Environmental

\begin{tabular}{|c|c|c|}
\hline Sub-Criteria & Mean & Standard Deviation \\
\hline Do you agree that there is a reduction of hazardous gas emission in your organization? & 4.03 & 1.161 \\
\hline $\begin{array}{l}\text { Do you agree that there is a reduction of discharge of Waste water in your } \\
\text { organization? }\end{array}$ & 4.07 & 1.143 \\
\hline Do you agree that there is a reduction of release of Solid waste in your organization? & 3.98 & 1.107 \\
\hline $\begin{array}{l}\text { Do you agree that there is a reduction of the use of hazardous /toxic material in your } \\
\text { organization? }\end{array}$ & 4.11 & 1.093 \\
\hline Do you agree that there is a decrement of the frequency of environmental disasters? & 4.07 & 1.096 \\
\hline
\end{tabular}

The most important sub-criterion for environmental is reduction of use of hazardous material with the mean value of 4.11 .

\section{Table 17}

Mean and Standard deviation of Sub criteria for Positive economic

\begin{tabular}{lcc}
\hline Sub Criteria & Mean & Standard Deviation \\
\hline Is there any decrement in material purchasing cost in your industry? & 3.47 & 1.200 \\
Is there any decrement in energy consumption cost in your industry? & 3.73 & 1.112 \\
Is there any decrement in waste treatment cost in your industry? & 3.51 & 1.177 \\
Is there any decrement in waste discharge fee in your industry? & 3.46 & 1.208 \\
Is there any decrement in fine for environmental disasters in your industry? & 3.65 & 1.332 \\
\hline
\end{tabular}

The highest mean value is for decrement in energy consumption cost i.e. 3.73. It is the most important factor. Decrement in waste discharge fee is the least important factor.

\section{Table 18}

Mean and Standard deviation of Sub criteria for Negative economic

\begin{tabular}{lll}
\hline Sub Criteria & Mean & Standard Deviation \\
\hline Is there any increment in Investment in your industry? & 3.87 & 1.100 \\
Is there any increment in operational cost in your industry? & 3.28 & 1.131 \\
Is there any increment in training cost in your industry? & 3.58 & 1.055 \\
$\begin{array}{l}\text { Do you feel that there is high cost of purchasing of environmental friendly } \\
\text { materials? }\end{array}$ & 3.70 & 1.066 \\
\hline
\end{tabular}

The most important sub criterion is increment in investment with highest mean value of 3.87.

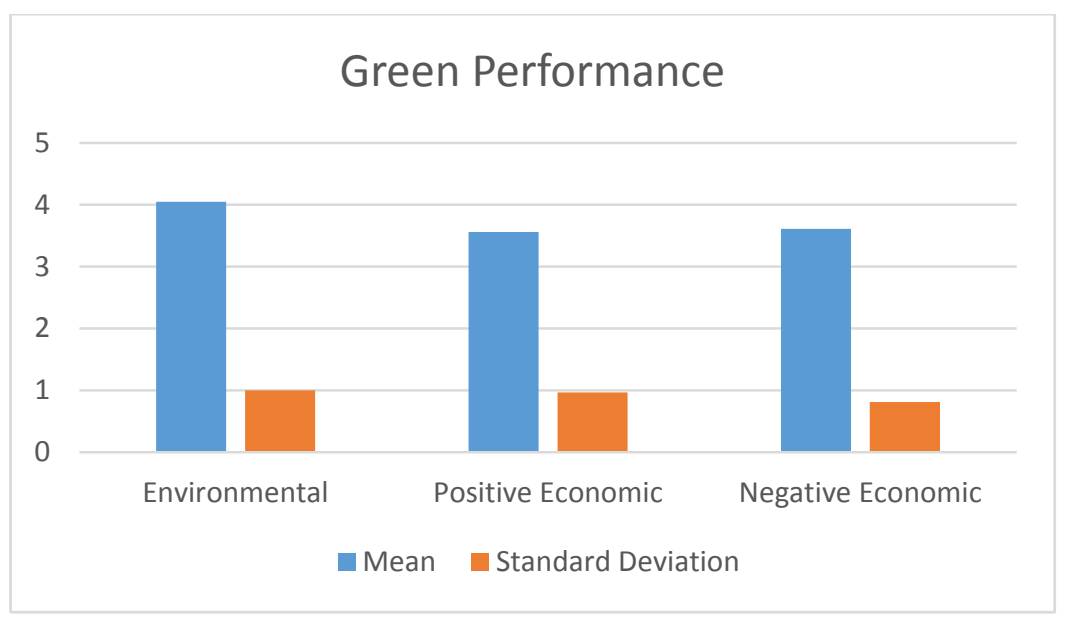

Fig. 5. The relative importance of major criteria in Indian manufacturing industries, mean value gives an indication of the important criteria of Green Performance 


\section{Table 19}

Importance of the Major criteria of Green Pressure

\begin{tabular}{lll}
\hline Criteria & Mean & Standard Deviation \\
\hline Regulatory & 4.48 & 0.685 \\
Competition & 3.90 & 1.132 \\
\hline
\end{tabular}

The most important criterion is regulatory with high mean value 4.48 .

\section{Table 20}

Mean and Standard deviation of Sub criteria for Regulatory and Competition

\begin{tabular}{lcc}
\hline Sub Criteria & Mean & Standard Deviation \\
\hline Does your organization follow Central government environmental regulations? & 4.61 & 0.774 \\
Does your organization follow Regional/State government environmental regulations? & 4.68 & 0.638 \\
Does your organization follow Regulation: EUP (The eco-design directive for energy & 4.08 & 1.150 \\
using products)? & & 0.925 \\
Does your organization follow Air (Prevention and control of Pollution) Act, 1981? & 4.48 & 0.840 \\
Does your organization follow water (Prevention and control of Pollution), 1974? & 4.50 & 0.873 \\
Does your organization follow Noise Pollution Act? & 4.49 & 0.925 \\
Does your organization follow Hazardous waste Handling and Management Act, & 4.51 & \\
1989? & 3.90 & 1.132 \\
\hline Does your organization compete with Green strategies of competitor industries? & & \\
\hline
\end{tabular}

The most important regulation is state government regulations with mean value of 4.68 and the least important sub-criterion is competition with mean value of 3.90 .

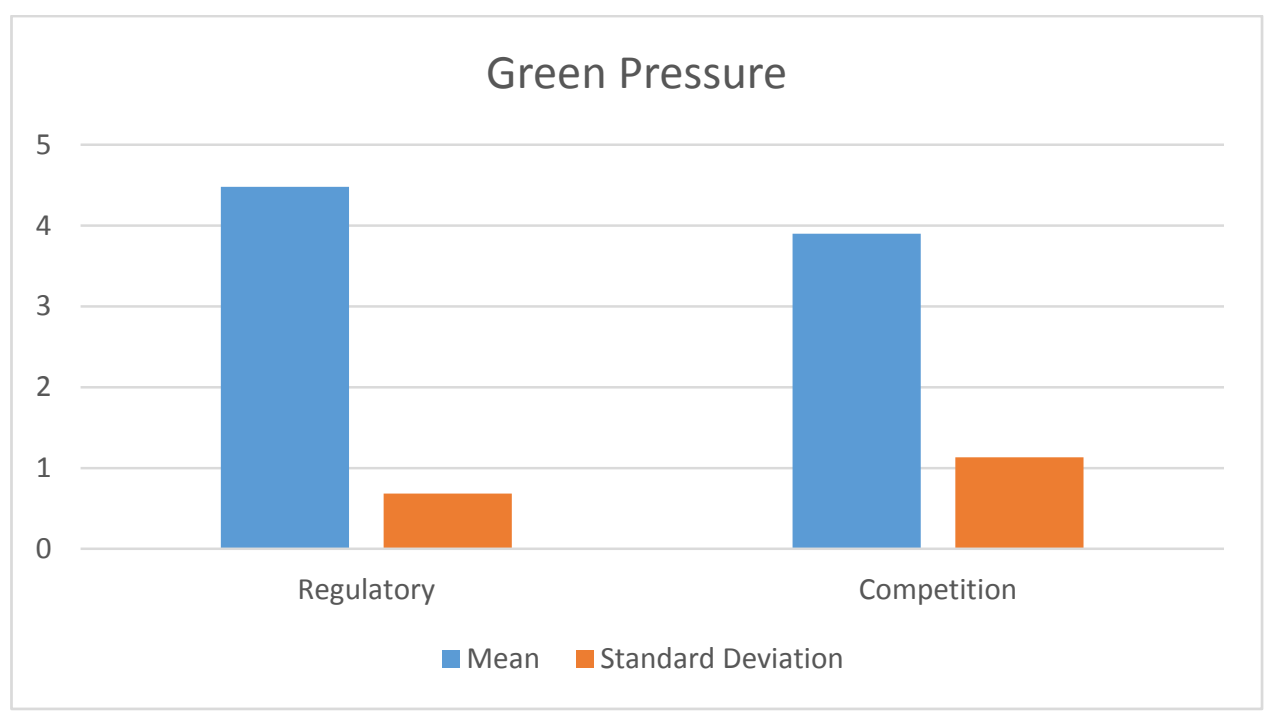

Fig. 6. The importance of major criteria in Indian manufacturing industries, mean value indicates the important criteria of Green Pressure

\section{Conclusion}

This paper has presented a survey to evaluate different facets of green supply chain practices, performance and pressure. Green supply chain is the new issue for Indian industries. This study has investigated the GSCM practice, performance and pressure adopted by different manufacturing industries in India. The research has indicated that the cooperation with costumers was the most important criterion for Indian industries in case of green practices. It is followed by internal recovery, eco designing, internal environmental management system, green packaging. The green purchasing that should be the most important criteria, occupies sixth position. It shows that Indian manufacturing companies cooperate with customers for eco designing, cleaner production, reverse logistics, green packaging etc. The most important criterion in case of green performance was associated with 
environmental factors followed by negative economic and positive economic. It means Indian industries focus on environmental issues such as removal of hazardous liquid waste, solid waste, gas emission etc. Regulatory was the most important criteria for green pressure.

\section{References}

Agarwal, G., \& Vijayvargy, L. (2012). Green supplier assessment in environmentally responsive supply chains through analytical network process. In Proceedings of the 2010 Int. Multi Conference of Engineers and computer scientists (Vol. 2).

Awasthi, A., Chauhan, S. S., \& Goyal, S. K. (2010). A fuzzy multicriteria approach for evaluating environmental performance of suppliers. International Journal of Production Economics, 126(2), 370-378.

Bhateja A. K., Babbar R., Singh S., Sachdeva A. (2011). Study of Green Supply Chain Management in the Indian Manufacturing Industries: A Literature Review cum an Analytical Approach for the measurement of performance, International Journal of Computational Engineering \& Management, 13, 84-99.

Büyüközkan, G., \& Çifçi, G. (2012). A novel hybrid MCDM approach based on fuzzy DEMATEL, fuzzy ANP and fuzzy TOPSIS to evaluate green suppliers.Expert Systems with Applications, 39(3), 3000-3011.

Chen, C. C., Shih, H. S., Shyur, H. J., \& Wu, K. S. (2012). A business strategy selection of green supply chain management via an analytic network process.Computers \& Mathematics with Applications, 64(8), 2544-2557.

Chandraker, R., \& Kumar, R. (2013). Evaluation and Measurement of Performance of GSCM in Chhattisgarh Manufacturing Industries (INDIA).International Journal of Application or Innovation in Engineering and Management (IJAIEM), 2(6), 240-249.

Chan H. K. (2011). Green process and product design in practice. Procedia - Social and Behavioral Sciences 25, $398-402$.

Deif, A. M. (2011). A system model for green manufacturing. Journal of Cleaner Production, 19(14), 1553-1559.

Deshmukh, S. P., \& Sunnapwar, V. K. (2013). Validation of Performance Measures for Green Supplier Selection in Indian Industries. International Journal of Modeling and Engineering Resources, 3, 1617-1622.

Govindan, K., Rajendran, S., Sarkis, J., \& Murugesan, P. (2013). Multi criteria decision making approaches for green supplier evaluation and selection: a literature review. Journal of Cleaner Production, 98(1), 66-83.

Muma, B. O., Nyaoga, R. B., Matwere, R. B., \& Nyambega, E. (2014). Green supply chain management and environmental performance among tea processing firms in Kericho CountyKenya. Management, 2(5), 270-276.

Huang, X., Tan, B. L., \& Dong, L. I. (2012). Pressures on green supply chain management: a study on manufacturing small and medium-sized enterprises in China. International Business and Management, 4(1), 76-82.

Humphreys, P. K., Wong, Y. K., \& Chan, F. T. S. (2003). Integrating environmental criteria into the supplier selection process. Journal of Materials Processing Technology, 138(1), 349-356.

Kumar, S., Chattopadhyaya, S., \& Sharma, V. (2012). Green supply chain management: a case study from Indian electrical and electronics industry.International Journal of Soft Computing and Engineering, 1(6), 275-281.

Liu, H., Chen, W., Kang, Z., Ngai, T., \& Li, Y. (2005). Fuzzy multiple attribute decision making for evaluating aggregate risk in green manufacturing. Tsinghua Science \& Technology, 10(5), 627-632.

Lin, C. T., Chen, C. B., \& Ting, Y. C. (2012). A green purchasing model by using ANP and LP methods. Journal of Testing and Evaluation, 40(2), 203-210.

Meera B. L., Chitramani P. (2014). Environmental Sustainability through Green Supply chain management practices among Indian Manufacturing Firms with special reference to Tamilnadu. International Journal of Scientific and Research Publications, 4(3), 2250-3153. 
Toke L. K., Gupta R. C. (2010). Dandekar M., Green Supply Chain Management; Critical Research and Practices, Proceedings of the 2010 Int. Conference on Industrial Engineering and Operations Management, Dhaka, Bangladesh.

Wu, K. J., Tseng, M. L., \& Vy, T. (2011). Evaluation the drivers of green supply chain management practices in uncertainty. Procedia-Social and Behavioral Sciences, 25, 384-397.

Yeh, W. C., \& Chuang, M. C. (2011). Using multi-objective genetic algorithm for partner selection in green supply chain problems. Expert Systems with Applications, 38(4), 4244-4253. 